\title{
Modern Approaches to Polymer Materials Protecting from lonizing Radiation
}

\section{A. I. WOZNIAK, V. S. IVANOV, O. A. ZHDANOVICH, V. I. NAZAROV and A. S. YEGOROV*}

The Federal State Unitary Enterprise Institute of Chemical Reagents and High Purity Chemical Substances of National Research Centre, Kurchatov Institute,107076,

Bogorodsky val, 3. Moscow, Russia.

*Corresponding author E-mail: egorov@ irea.org.ru

http://dx.doi.org/10.13005/ojc/330502

(Received: July 04, 2017; Accepted: August 15, 2017)

\begin{abstract}
This review describes main types of organic polymers, which are now widely used and are the most resistant to ionizing radiation. It presents modern approaches to creation of radiationshielding composite materials based on polymer matrix and various types of fillers. It also discusses the efficiency of sizes of fillers' micro- and nanoparticles in terms of improving radiation resistance of organic polymer materials.
\end{abstract}

Keywords: radiation resistant polymers, polymer composite materials, radiation shielding, radiation absorbing fillers

\section{INTRODUCTION}

High energy radiations of alpha and beta particles, $\mathrm{X}$-rays and gamma rays and neutrons are often used in a wide range of industries, including nuclear power, healthcare and aerospace industry. Undesirable effects of any type of emission may be life threatening. The consequences of such effects are related to a number of factors, which include type of emission and its energy, absorbed dose amount, exposure period and the like. Health hazards of radiation include cancerogenesis, heart diseases, cataract and other acute radiation-related symptoms ${ }^{1}$. Damage to nervous system is a potential issue related to heavy ions contained in galactic cosmic rays ${ }^{2}$.
The employees of nuclear power plants and space stations who are the most exposed to neutron radiation ${ }^{3,4}$. Neutron radiation occurs during nuclear reactions into nuclear reactors, industrialand laboratory-scale plants and nuclear explosions. Due to the lack of charge or poor interaction with a substance,neurons possess an extremely high penetrating power that depends on their energy and constitution of the substance's atoms they interact with. String ionizing effect is caused by neutron's secondary radiation (charged particles or gamma quanta) when colliding with a nucleus or electron. lonizing radiation of high energies (up to tens of $\mathrm{MeV}$ ) is used to control tumor propagation as a part of cancer treatment or treat benign diseases. However, tissues around the treated area 
are frequently exposed to X-rays, which results in adverse side effects for internal and external organs $^{5,6}$. X-rays with their energy range of several keV are often used in interventional procedures and diagnostic radiology (Table 1 ).

As new sources of energy are being further developed, radiation protection, i.e. selection and creation of new radiation-shielding materials, becomes of crucial importance. Virtually all materials, which are used in manufacturing various structural units and working sections of nuclear and thermonuclear facilities, are exposed to radiation during their operation, which results in their structural changes, which means changes in the ir strength, electrical and other characteristics.

Any material absorbs radiation to a certain degree. In particular as a rule alpha radiation is completely absorbed without any particular complications. Beta radiation does not require additional protection and safety measures too. The problem is how to protect from neutron and gamma radiation. It includes, effective insulation of longlasting radiation when, say, storing radioactive wastes, on the one hand, and protection from temporary and irregular emissions, which occur when operating $X$-ray equipment or carrying out various scientific or technical experiments, on the other hand.

Materials' radiation resistance significantly varies depending on the type of radiation, absorbed dose amount/rate, radiation mode (continuous or pulsed, short-term or long-term), material's operating environment (temperature, high pressure, mechanical loads, magnetic or electric field), material's sample dimensions, its specific surface area and other factor. Alterations in materials can be reversible or irreversible, and occur either immediately after radiation effect or over a long period after radiation event.

Radiation resistance of inorganic substances depends on their crystal structure and the type of chemical bond $d^{9,10}$. It is substances with ionic lattice that are the most stable ones. Dense structures with a high degree of symmetry are the most resistant to radiation effects. Glasses are featured by Alterations/modifications in transparency, coloring and possible crystallization. Silicates' exposure to radiation results in anisotropic expansion of their

Table. 1: Summary of various radiation sources used or found in the three above-mentioned industries ${ }^{3,5,7,8}$

\begin{tabular}{|c|c|c|c|}
\hline Industry & Radiation source & Radiation composition & Energy range \\
\hline \multirow[t]{3}{*}{ Aerospace } & $\begin{array}{l}\text { Galactic cosmic } \\
\text { rays }(G C R)\end{array}$ & $\begin{array}{l}\text { High energy protons, } \alpha- \\
\text { particles and heavy nuclei } \\
\text { ( } 85 \%, 14 \% \text { and } 1 \% \text { of the } \\
\text { total flux respectively). }\end{array}$ & $10 \mathrm{MeV}$ to $10 \mathrm{GeV}$ \\
\hline & $\begin{array}{l}\text { Solar cosmic ray } \\
\text { (SCR) event }\end{array}$ & $\begin{array}{l}\text { A transient event of low- } \\
\text { to-medium energy protons } \\
\text { and } \alpha \text {-particles }\end{array}$ & $\begin{array}{l}\text { Several MeV to } \\
\text { hundreds of } \mathrm{MeV}\end{array}$ \\
\hline & $\begin{array}{l}\text { The Earth's trapped } \\
\text { particle radiation belt }\end{array}$ & $\begin{array}{l}\text { High energy electrons } \\
\text { and protons }\end{array}$ & $\begin{array}{l}\text { Electrons: Several MeV } \\
\text { Protons: several hundreds }\end{array}$ \\
\hline $\begin{array}{l}\text { Medical radiology: } \\
\text { therapy diagnostics, } \\
\text { interventional and }\end{array}$ & $\begin{array}{l}\text { Gamma rays } \\
\text { and } X \text {-rays } \\
\text { rays and } X \text {-rays }\end{array}$ & $\begin{array}{l}\text { Electromagnetic radiation } \\
\text { with wide-range gamma }\end{array}$ & $\begin{array}{l}\text { of MeV Tens of keV to } \\
\text { tens of } \mathrm{MeV}\end{array}$ \\
\hline radiation therapy & Protons and electrons & Therapeutic radiation & \\
\hline \multirow[t]{2}{*}{ Nuclear energy } & Particle emission & $\begin{array}{l}\text { Alpha and beta particles and } \\
\text { neutrons }\end{array}$ & $\begin{array}{l}\text { Up to } 15 \mathrm{MeV} \text { (neutrons), } \\
\text { up to } 4 \mathrm{MeV} \text { (alpha and beta } \\
\text { particles) }\end{array}$ \\
\hline & Gamma radiation & Gamma rays & $10 \mathrm{keV}$ to $3 \mathrm{MeV}$ \\
\hline
\end{tabular}


crystals, amorphization of its structure and reduction in density, resilience and thermal conductivity. When exposed to ionizing radiation, metal properties change depending on the damages made to their crystal lattice. Single defects normally strengthen a metal, yet reduce its plasticity. Electrical resistance of metals or alloys increases due to the emergence of defects, yet it may decrease if the radiation results in simplifying alloy structures. Semiconductors always have a certain concentration of point defects, which reaches equilibrium under a particular temperature. While exposed to radiation, this concentration raises, which results in changes in electrical and optical properties.

Interaction between ionizing radiation and organic compounds is accompanied by formation of intermediate active particles, destruction, oxidation, linking, gas formation, depolymerization (polymers) etc. Reversible changes in organic materials are caused by the establishment of static equilibrium between generation and destruction of unstable radiolysis products, and depend on the exposure dose rate. Radiation resistance, including that of polymers, also varies depending on the volume of atmospheric oxygen dissolved in them and the rate of its intake from outer environment. Radiation-related chemical oxidation of a substance occurs in presecne of oxygen. The most significant structural changes in organic polymer materials caused by radiation occur during destruction and linking of polymer molecules. It results in substantial changes in chemical and thermal resistance of substances, ultimate strength, elastic modulus, dielectric permittivity, electric strength and electrical conductivity. The presence of double and conjugated bonds, aromatic rings and heterocyclic fragments obviously improves radiation resistance of organic compounds.

Various protective materials, e.g. concrete, polymer composites and heavy metals, such as lead, lead/tungsten/tin oxide composites and the like ${ }^{11,13}$, are used for attenuating or absorbing an unpleasant radiation. The efficiency of shielding these materials significantly varies depending on the type of radiation and energy range ${ }^{14}$. Lead and other metals with large atomic mass are used to attenuate high energy radiation, such as $\mathrm{X}$-rays and gamma rays. Metals are not always capable of blocking all types of radiation, notably neutron emissions in space or nuclear laboratories. The presence of boron oxide in the composites of concrete and vitrified colemanite $\left(\mathrm{CaB}_{3} \mathrm{O}_{4}(\mathrm{OH})_{3} \cdot \mathrm{H}_{2} \mathrm{O}\right)$ results in improving the absorption of thermal neutrons, while the inclusion of polystyrene into concrete composites improves the ability to shield fast neutron flux ${ }^{15}$. However, radioactive-shielding hardware made of these materials is heavy and bulky, which is unwelcome for the most of applications. For example, in case of mobile nuclear facilities and manned spaceships, lighter and more compact radiation-shielding materials are preferable due to the reduction of installation area and higher mobility, which are demanded from such devices $^{16}$.

Due to their sets properties (light weight, low dielectric constant, resistance to corrosive environments and organic solvents, ability to produce both rigid and flexible framework structures), organic polymer materials are widely used in all fields of activity, including those exposed to higher radiation hazard: microelectronics, aerospace industry, gas separation, fuel cell manufacturing; matrices for creating reinforced composites based on light carbon fibers and designed for replacing metal parts relevant to the aerospace industry and spacecraft body parts; and cable industry (production of electrically insulating lacquers and enamels) ${ }^{16}$. As a rule, polymer materials' resistance to ionizing radiation is limited by their mechanical properties, since they turn fragile and lose their ability to withstand mechanical loads.

\section{Radiation resistance of organic polymers}

In general, radiation material science determines radiation resistance as a threshold dose value, which correlates with a preset relative change in material properties (including polymer ones) caused by radiation ${ }^{17,18}$. Polymer's radiation resistance depends, above all, on its nature and reflects its physical and chemical resistance, on the one hand, and technical and operating capability under ionizing radiations, i.e. during operation of nuclear and ther monuclear reactors, electron accelerators and radioisotope plants, as well as in space environment and the like. 
Assessment of polymers' radiation resistance also takes into consideration their elemental composition, which has an utmost importance in terms of neutron radiation, phase composition and defectiveness (radiation-related chemical transformations are reported to a greater degree for viscous or viscous-flow amorphous states). Structural degradation processes in polymers are accelerated by the rise in temperature and combined effect of ionizing radiation, UV-light, visible light and IR-light. Not only radiation resistance, but also the direction of basic radiationrelated chemical processes is substantially depend on polymer microstructure, in accordance with which all materials are divided into mainly linking and destructive ones (Table2) ${ }^{19}$.

The presence of unsubstituted double bonds, aromatic cycles and conjugated fragments in the macromolecule enables the formation of crosslinked structures during the scattering of ionizing radiation.

Table.2 : Polymer classification

\begin{tabular}{|c|c|}
\hline $\begin{array}{l}\text { Crosslinking } \\
\text { polymers }\end{array}$ & $\begin{array}{c}\text { Destructive } \\
\text { polymers }\end{array}$ \\
\hline Polyethylene & Polyisobutylene \\
\hline Polypropylene & Butyl rubber \\
\hline Polystyrene & Polymethylstyrene \\
\hline Polyvinylchloride & Polymethacrylate \\
\hline Acrylate polymers & Polymethacrylamide \\
\hline Polyamides & Polytetrafluoroethylene \\
\hline $\begin{array}{l}\text { Phenol-formaldehyde } \\
\text { resins }\end{array}$ & Pulp and its derivatives \\
\hline \multicolumn{2}{|c|}{ Amino-formaldehyde resins } \\
\hline \multicolumn{2}{|l|}{ Epoxy resins } \\
\hline \multicolumn{2}{|l|}{ Polyacrylimide } \\
\hline \multicolumn{2}{|l|}{ Polyimides } \\
\hline
\end{tabular}

For the purpose of comparative estimation of the possibility of using a particular type of polymer materials as a radiation-shielding base of a composite, a number of parameters, such as material's ability to stop ionizing particles, ionizing radiation absorption rate or radiation output of crosslinking/destruction under radiation, are taken into consideration ${ }^{19}$. The values of ionizing radiation absorption rate, at which the strength decreases by half (in-air radiation at room temperature), for a number of polymers are demonstrated in Table 3. Polystyrene and polyethylene terephthalate fibers turn unsuitable for use after absorbing the dose of 5 MGy. Ladder-type organosilicon polymers ${ }^{20}$ and aromatic polyamides ${ }^{21,24}$ are a slightly more stable, yet they show significant changes in their infrared spectrum after absorbing the dose of $30 \mathrm{MGy}^{25}$. To improve of improving radiation resistance of a typically destructive polymer, polyisobutylene, its macromolecule chain is modified by adding monomer units of styrene, to produce random linear isobutylene styrene copolymer (to provide internal protection). Improving radiation resistance by adding polystyrene to the molecule structure is also reported for polymer films of nanostructured polyglycidyl methacrylate ${ }^{26}$. Addition of 2-vinylnaphthalene (3-5\%) as an antirad for polyvinyl chloride substantially inhibited oxidation and dehydrohalogenation processes and improved radiation resistance of the material. ${ }^{29}$ However, it is important to bear in mind the crossimpact of organic compounds of different nature, which results in aromatic fragments becoming more sensitive to ionizing radiation. ${ }^{28}$

Table.3 : Radiation dose absorbed by polymer and accompanied by $50 \%$ decrease in strength

\begin{tabular}{lc}
\hline Polymer & D, MGy \\
\hline Polytetrafluoroethylene & 0.01 \\
Polytrifluorochloroethylene & 0.03 \\
Polymethylmethacrylate & 0.3 \\
Polycaprolactam & 0.6 \\
Polypropylene & 1 \\
HD polyethylene & 1 \\
Polyvinylchloride & 1,5 \\
Polyethyleneterephthalate & 2 \\
Triethyleneglycol dimethacrylic & 2 \\
ester TGM-3 & \\
LD polyethylene & 3 \\
Polyurethanes & 3 \\
Melamine for maldehyde resin & 4 \\
Polycarbonate & 5 \\
Polystyrene & 5 \\
Epoxy resin $E D-10$ & 15 \\
ETZ-10 & 30 \\
Epoxyphenol carbon-fiber & 30 \\
composite KMU-1L & \\
Epoxyphenol carbon-fiber & 30 \\
composite KMU-4L & \\
\hline
\end{tabular}


One of the most radiation-resistant polymer classes is polyimides Fig. ${ }^{29-31}$. This polymer withstands the effects of ionizing radiations equivalent to the absorption doses of up to $10^{7} \mathrm{~Gy}$.

Poly-4.4'-diphenylene oxide pyromellitimide $\left(\mathrm{Ar}_{1}=\mathrm{Ph}\right)$ films retain their good mechanical and electrical characteristics after high energy electron radiation, with the absorption dose of $10^{2} \mathrm{MGy} .^{32}$ Interms of radiation resistance polyimides are not inferior even to polysulfone ${ }^{33}$. A polypyromellitimide $\left(\mathrm{Ar}_{1}=\mathrm{Ph}\right)$ film based on diaminodiphenylmethane $\left(\mathrm{Ar}_{2}\right)$ does not lose its flexibility after absorbing the gamma radiation dose of 100 MGy. After absorbing the neutron dose of 3.5.10 ${ }^{19}$ neutrons per $1 \mathrm{~cm}^{-2}$ at the temperature of $175^{\circ} \mathrm{C}$, PMtype polyimide films turn dark and get fragile, yet under less harsh conditions, with the absorption dose of 1.4.10 ${ }^{19}$ neutrons per $1 \mathrm{~cm}^{-2}$ and at the temperature of $50-75^{\circ} \mathrm{C}$, they just slightly get dark ${ }^{34}$. DFO-type polyimide withstands the neutron flux of $3 \cdot 10^{18}$ neutrons per 1 $\mathrm{cm}^{-2}$ without any noticeable changes in its properties or appearance ${ }^{35}$. Such absorption doses have a destructive effect on other carbonchain polymers.

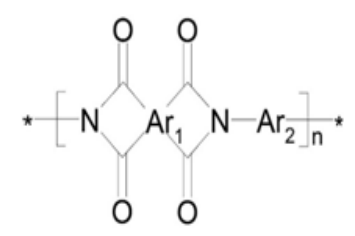

Fig.1. Structure of polyimide unit

Long-term (over 28 to 42 months) operation of industrial polyimide films PM-1E and Kapton $100-\mathrm{HN}$ at the Near-Earth orbit in both exposed or shielded states results in signification reduction in their transparency within UV- and visible range and surface hydrophilization due to the increase in the number of polar groups on samples' surface, notably acylradicals ${ }^{36}$. Multilayer packages of polyimide films coated with gold, aluminum and silicon monoxide provide spacecraft's temperature control.

High radiation resistance of polyimide matrices caused by their ability to scatter large doses of absorbed energy, large energy consumption for breaking imide heterocycle and specific structuring of the macromolecules exposed to radiation ${ }^{37}$. High thermal resistance and thermal oxidation resistance of polyimide matrices, compared with the most carbon-chain polymers of other types, also greatly adds to their stability. Under the conditions of long-term isothermal heating, the mass of poly-4.4'-diphenylene oxide pyromellitimide after $15 \mathrm{~h}$. heating in the inert atmosphere at the temperature of $400^{\circ} \mathrm{C}, 450^{\circ} \mathrm{C}$ and $500^{\circ} \mathrm{C}$ decreased by $1.5,3.0$ and $7.0 \%$ respectively ${ }^{38}$.

Production of synthetic polymer materials, that are not inferior to metal ones in terms of strength, while having significantly lower density, higher corrosion resistance, good heat and electrical insulation characteristics and radiation-shielding properties, as well as processability into products, contributed to the acceleration of the trend to replace metal products with polymer parts, structures and coatings in a large number of industries. However, when operating under higher radiation conditions, particularly those accompanied by hightemperature and oxidizing effects, polymers are prone to substantial destruction. These structural changes can be prevented in several ways ${ }^{39}$ passive protection (shielding), physical and chemical modification of material and radiation and heat treatment

\section{Radiation-resistant and radiation-shielding composite materials}

Polymer composite materials are widely used in various fields of modern industrial manufacturing, $\mathrm{He}$ is due to their relatively high process ability into finished products. Bakelite, which produced since 1916 on the basis of fiberfilled phenol-formaldehyde resin (wood flour), is considered to be the first such material is considered. At present, there are over 10000 items of known filled polymers. Fillers perform two main functions: cutting material costs and providing it with special properties.

There is a growing demand for developing new protective materials, which can be modified in accordance with specific applications (or type of radiation). During the last two decades the practical study of nano and micro composites to attenuate/ absorb high energy radiation have been commenced. Due to high ratio between surface area and volume, nanoparticles have an enhanced ability to absorb photons ${ }^{40}$. Using nanosized materials in radiation-shielding composites with 
polymer matrices is also due to poor adhesion of matrix materials, radiation-absorbing ceramic particles and nanoparticles of heavy metals used as gamma-ray and $\mathrm{X}$-ray absorbing fillers. Using nanosized powder particles of radiation-absorbing materials $\left(\mathrm{BN}, \mathrm{B}_{4} \mathrm{C}, \mathrm{Pb}\right.$ and $\mathrm{W}$ ) results 1.5-fold increase in neutron absorption ratio and 30 -to- $40 \%$ increase in gamma-radiation scattering ratio.

It was demonstrated that, in addition to radiation resistance, composite materials had higher mechanical strength and thermal stability, compared with a polymer without fillers ${ }^{16,41-46}$. Relatively small amount of nanofiller is enough for improving properties of CNT-based polymer composites, which are featured by exceptionally high values of elastic modulus and tensile strength (of up to $1 \mathrm{TPa}$ and tens or hundreds GPa respectively), and also thermal and electrical conductivity and high in-air oxidation resistance $\left(>700^{\circ} \mathrm{C}\right)$, without losing their elasticity ${ }^{44,47,48}$. Micro- and nanomaterials scattered in polymer matrix can be used for developing effective radiation protection, including their application as an alternative to metal structural materials ${ }^{49,50}$.

High elasticity, resilience and stability of rubber's form have made it quite a wide-spread matrix material for creating radiation-shielding materials. Calendering natural or synthetic rubber filled with radiation-shielding compositions allows to produce a wide range of protective materials and products. When added to polymer matrix, fillers of inorganic nature improve mechanical characteristics of the composition ${ }^{51}$.

There is a number of known X-rayshielding materials based on the rubber made of synthetic or natural rubbers, which are filled with lead compounds, such as highly scattered metal lead $^{52}$, litharge ${ }^{53}$, fatty acid salts and metalorganic compounds ${ }^{54,55}$. The materials produced by such method contain a large amount of filler, which results in degradation of polymer's operating characteristics. Moreover, due to high lead toxicity, industrial production of lead-containing rubbers belongs to the class of industries with particularly harmful working environment, while the products are featured by a poor lead fixation in the carrying matrix of the mentioned material, so lead falls out of the rubber and, due to its toxicity, causes contaminations of X-ray rooms and employees' clothes and hands, which are hazardous to health, during operation. to tackling this phenomenon, all personal protective equipment made of leadcontaining rubber are completely shrouded with polymers or other materials, which are easy to decontaminate, in accordance with instructions of the Ministry of Healthcare.

Another method of creating radiationshielding rubber materials is to use compounds of rare earth elements, including those combined with tin (IV) or antimony (III) compounds, as fillers. ${ }^{56-58}$ Such composites are used as a material that protects personnel from radiation and X-rays: protective gloves, aprons, high boots, mats and other products.

Polyethylene-based compositions protecting from neutron radiation have become widespread too, since polyethylene has the highest concentration of hydrogen nuclei of per $1 \mathrm{~cm}^{-3}\left(7.5 \cdot 10^{22}\right)$. The material containing 3-5 weight fractions of amorphous boron per 100 weight fractions of polyethylene is usually used as standard ${ }^{59,60}$. This material is highly functional (i.e. can be used for manufacturing large sheets and plates) and possesses acceptable sanitary and hygienic properties. The disadvantage of such composition is a low thermal resistance, which makes it impossible to use it over a long period of time within the temperature range of 150 to $200^{\circ} \mathrm{C}$ even if there are suggested stabilizers. Besides, according to existing data, at the temperature exceeding $70^{\circ} \mathrm{C}$ polyethylene-based products are unsuitable for use when coming into contact with metal ${ }^{60}$. Admixing of addtitional components (antipyrenes reducing combustibility) diminishes protective characteristics, which may result in degradation of massdimensional characteristics of a item.

In case of high filler loading capacity, halogencontaining additives, metal oxides and hydroxides are used as fire resistant additives. Using chlorine containing components to reduce protective materials' combustibility is inappropriate, since chlorine and its compounds are highly aggressive. There are also selfextinguishing polyolefin compositions, which include polyethylene, antimony compounds and boron- 
containing aromatic compounds. Addition of $\mathrm{Sb}_{2} \mathrm{O}_{3}$ has an insignificant effect on improving fire resistance. Since boron-containing compounds are poorly compatible with polyethylene and literally "evaporate» from it, ethylene vinyl acetate copolymer, rubbers and octamethylcyclosiloxane are added to reduce evaporation rate. However, a palpable reduction in evaporation of boroncontaining compounds requires large amounts of both vinyl acetate copolymer and rubbers. For example, noticeable reduction in evaporation of boron-containing compounds by adding rubbers is palpable at $15 \% \mathrm{wt}$, while the addition of such amount of rubbers results in rising combustibility of a composite material, which, in turn, requires the increase in the content of boron-containing compounds in the material and causes degradation of strength properties ${ }^{61}$.

Like a polyethylene, polypropylene is also used as a matrix for protective compositions. Polypropylene matrix is modified in several ways, using several types of radiation-shielding fillers, which include powdered tungsten and powdered iron of various scattering degrees ${ }^{62}$.

Improvement of composition's mechanical characteristics based on polymer matrix is known ${ }^{63,64}$ to depend not only on the amount of filler to be added, but also on the particle size of the latter. As a rule, the smaller filler's particle size is, the larger the specific surface of the latter is, and the larger amount of polymer it takes to capsulate particles of required mechanical strength of the products made of this composition. A solid filler, with its particle sizes exceeding those of supramolecular formations of the polymer, often acts as an adsorbent, with polymer molecules adsorbed on its surface. It is accompanied by formation of highly oriented adsorption layers, which contribute to improving mechanical strength of the polymer material. Most of modern projects on creating new radiationshielding materials are carried out with refer to filler's particle size ${ }^{65}$.

\section{Polymers filled with micro - and nanocarbon fillers}

Polymer materials filled with graphite fiber have an exceptionally high mechanical strength, so they are used for replacing metals having insufficient mechanical properties or high density. Modification ${ }^{68}$ of graphite microfibers by intercalating $\mathrm{Br}_{2}$ and $\mathrm{IBr}$ results in improving the efficiency of protection against high energy photons ( $\mathrm{X}$-rays and gamma rays with their energies of 13 and $46.5 \mathrm{keV}$ respectively). Such composite is suggested for use as a protection of spacecraft's power systems against electromagnetic interferences.

Using carbon nanotubes are suggested for improving radiation resistance and mechanical strengthen of water-containing polymers ${ }^{66,67}(\mathrm{CNT})$. It was shown ${ }^{66}$ that addition of CNT to polymethyl methacrylate matrix (PMMA) caused reduction in the depth of sample etching with high energy radiations (UV, ozone and electronic ray with the energy of $20 \mathrm{keV})$, until it reached percolation barrier of the CNT network (at $0.5 \%$ wt of CNT) inside polymer matrix. Having reached this concentration, etch depth changes less significantly. Percolation barrier is a saturation point of shielding properties of the CNT network, which has been confirmed by surface resistance measurements. The authors have concluded that addition of CNT results in significant improvement of radiation resistance by inhibiting radiation-induced PMMA degradation and effective scattering of radiation.

To be used in spacecraft, not only do structural materials need to radiation-resistant and have mechanical strength, but they also must withstand thermal cycling. Matrix of poly(4-methyl1-pentene) (PMP) with $0.5 \%$ wt of single-walled CNT (SWNT) has been suggested ${ }^{67}$ as an alternative to polyethylene (PE) to be used as protective material against GCR, due to superb properties of this material compared with $\mathrm{PE}$. As dynamic mechanical analysis (DMA) of non-filled PMP and a composite (PMP+) (PMP+0.5\% wt of SWNT) showed, addition of SWNT improves viscoelastic properties of the composite, while elastic modulus and loss modulus turned to be higher than those of non-filled polymer. DMA also showed that addition of SWNT raises the temperature of composite vitrification and increases the intensity of relaxation within amorphous area of PMP, which means carbon nanotubes improve the crystallinity and mechanical properties of PMP. 
Having been exposed to the proton beam with its energy of $2 \mathrm{MeV}$ and fluence range of $10^{13}$ to $10^{15} \mathrm{~cm}^{-2}$, nanocomposites ${ }^{68}$ based on polydimethylsiloxane (PDMS) with $1 \%$ wt of detonation-synthesized nanodiamond (PDMS-DSNA), zinc oxide (PDMS-ZnO) and SCNT (PDMS - SCNT) show structural degradation with the fluence of almost twice as much at that of PDMS without fillers. Nanofillers $\mathrm{ZnO}$, SWNT and DSNA participate in protecting polymer matrix of PDMS from degradation and provide almost the same level of protection at low proton fluence $\left(10^{13} \mathrm{~cm}^{-2}\right)$, yet at higher values of flux density $\left(10^{14}-10^{15} \mathrm{~cm}^{-2}\right)$ it is ZnO and DSNA that provide a better protection.

In the course of radiation test run by the NASA Space Radiation Laboratory, it was found ${ }^{69}$ that modification of polymer matrix with graphite's reactive nanofibers significantly improves mechanical (strength, elastic modulus and hardness) and thermal properties, and also wetting property and adhesion strength when coating UHMWPE with fibers, compared with non-modified matrix, without reduction in material's radiation resistance.

\section{Polymers containing micro- and nanosized inorganic fillers}

Using lead and its compounds as fillers still matters. Despite its specific plasticity, a method of producing ${ }^{70}$ nanosized lead powder in the highpower ball mill, using polyvinyl alcohol (PVA) as a supplementary agent, has been developed. Using PVA slows down cold bonding of formed lead nanoparticles. Optimal duration of disintegration to achieve a more precise size is $60 \mathrm{~min}$ and results in a powder with the average size of its crystallites of up to $68 \mathrm{~nm}$. The powder produced was used to produce polypropylene-based nanocomposite for manufacturing materials that shield gamma radiation.

New radiation-shielding nanocomposites based on conductive polymer and lead salt have been suggested for attenuating $\mathrm{X}$-rays $\mathrm{s}^{71}$. Polypyrrole/Lead nanocomposites are produced by easy-to-use method of lead chemical reduction with in the solution, using lithium hydride activated by lithium tert-butoxide, and also chemical polymerization (in situ) over dodecylbenzene sulfonic acid as a dopant and a surface-active substance, and iron chloride as an oxidizer. Linear attenuation coefficient, attenuation percentage and thickness of semi-attenuation of samples bearing various lead loads and having the thickness at the photon energy of $13.95,17.74$, $20.08,26.34$ and $59.50 \mathrm{keV}$ were measured to assess radiation-shielding properties on nanocomposites. According to the test results, the values of attenuation coefficient, thickness of semiattenuation and other protection parameters vary depending on energy, chemical composition and thickness of the samples. As variations/fluctuations in attenuation coefficient caused by frequency showed, the ability to attenuate gamma radiation improves with the increase in the concentration of lead nanoparticles. The impact of sample's thickness on protective properties was considered too: $100 \%$ absorption was reported at the energy of $20.08 \mathrm{keV}$ or less with the thickness of $0.6 \mathrm{~m}$ (polypyrrole/lead of $40 \%$ $w t)$. At the energy of $59.50 \mathrm{keV}$, the absorption rate of this composite exceeded $50 \%$.

Composite sheets based on silicon rubber and filled with various amounts of litharge (15-42\% wt.) were produced and studied for the purpose of using them as protective materials against gamma radiation ${ }^{72}$. Shielding properties of the composite (linear attenuation coefficient $(\mu)$ and attenuation coefficient $(\mu / \rho)$ were studied using three point sources of radiation $\left({ }^{232} \mathrm{Th},{ }^{137} \mathrm{Cs}\right.$ and ${ }^{22} \mathrm{Na}$ ) within the energy range of 238 to $1275 \mathrm{keV}$. As expected, rising lead concentration was accompanied by improvement of protective properties, yet it was discovered that addition of filler to the rubber matrix is one of the main factors, which improve physical and mechanical properties, with the best results achieved at the litharge concentration of $35 \% \mathrm{wt}^{72}$.

Currently used lead products are heavy and bulky, and a lead filler itself is toxic. As the frequency of using $X$-ray radiation in diagnostics and therapy procedures has increased, so have the demand in developing work wear for protecting personnel from radiation. Composites based on polyether matrix and magnetite (Mag) and ilmenite (IIm) fillers have been produced for radiationshielding at medical institutions, in hot laboratory chambers and the like ${ }^{73}$. In both cases, boron carbide $\left(\mathrm{B}_{4} \mathrm{C}\right)$ was added to composites' compositions. The composition of composite 
polyether/Mag, with its density of $2.75 \mathrm{~g} / \mathrm{cm}^{-3}$ is as follows: polyether of $17.5 \% \mathrm{wt}$, magnetite of $72.5 \%$ wt and $\mathrm{B}_{4} \mathrm{C}$ of $10 \% \mathrm{wt}$. The composition of composite polyether $/ 1 \mathrm{~m}$, with its density of $2.7 \mathrm{~g} / \mathrm{cm}^{-3}$ is as follows: polyether of $15 \%$ wt, ilmenite of $75 \%$ wt and $\mathrm{B}_{4} \mathrm{C}$ of $10 \%$ wt. Both magnetite and ilmenite used in this study were produced by disintegration of commercially available ores, with the average filler size of $500 \mu \mathrm{m}$.

It was demonstrated ${ }^{74}$ that bismuth oxide $\left(\mathrm{Bi}_{2} \mathrm{O}_{3}\right)$, which belongs to a lower hazard class compared with lead, was a suitable alternative to it. Light fabrics protecting from $\mathrm{X}$-ray radiation and having similar attenuating effect can be manufactured by coated their surface with bismuth oxide (concentration exceeding $50 \%$ ).

Nanocomposite ${ }^{75}$ based on polydimethylsiloxane (PDMS) with $\mathrm{Bi}_{2} \mathrm{O}_{3}$ of $44.44 \%$ wt and the thickness of $3.73 \mathrm{~mm}$ was capable of attenuating all scattered $X$-rays forming in the tube at the potential of $60 \mathrm{kV}$, which is normally used in interventional radiology procedures.

Detailed analysis of radiation-caused damages is important for long-term use of radiation shields based on $\mathrm{PDMS} / \mathrm{Bi}_{2} \mathrm{O}_{3}$. Compared with conventional $\mathrm{X}$-ray-shielding materials, PDMS nanocomposites are non-toxic, cost-effective and easy to manufacture (since they do not need industrial heavy metal extruders and compressors, as most of currently commercially-available shields do). However, to achieve the attenuation rate comparable to with of commercially-available vinylor lead-based shields $(97.5 \%$ and $98.7 \%$ respectively at $102 \mathrm{kV}$ ), ${ }^{76}$ it is necessary increase either the content of bismuth oxide or the thickness of nanocomposites. Material PDMS $/ \mathrm{Bi}_{2} \mathrm{O}_{3}$ with bismuth oxide content of $44.44 \%$ wt, which shielding properties are equivalent to that of $0.25-\mathrm{mm}$ thick lead sheet is 3.73-mm thick, and its weight is twice as much as that of $0.25-\mathrm{mm}$ thick lead sheet. It is important to note that these nanocomposites can be applied as coating or paint, so they can take any required shape.

Powdered molybdenum additive was used to improve epoxy material's shielding properties against neutron flux ${ }^{77}$. According to the results of simulation carried with/by Monte-Carlo method total macroscopic value of neutron capture cross-section increased from 0.1597 to $0.4522 \mathrm{~cm}^{-1}$. It was accompanied by a $12 \%$ increase in equivalent attenuation dose in the test results.

Tungsten/epoxy composites (W/EP) were produced by mixing epoxy resin with powdered tungsten with various values of weight percentage. ${ }^{78}$ Mechanism of radiation-caused degradation was studied in accordance with changes in the concentration of free radicals and thermal and mechanical properties of composites. As the results show, as the convent of tungsten increases, so does the thermal resistance of composites. However, as radiation absorption dose increases, thermal and mechanical properties of composites degrade, then slightly improve, and rapidly degrade again in the end, due to the competition between chain-braking and cross-linking reactions caused by gamma radiation. Linear attenuation coefficient of W/EP increases from 0.08 to $0.27 \mathrm{~cm}^{-1}$, while the content of tungsten rises from $0 \%$ to $80 \%$ wt. A small amount of tungsten reinforces epoxy resin, while further increase in tungsten load leads to rapid reduction of composites' bending strength from 111.2 to 94,2 MPa due to tungsten agglomeration.

Radiation can cause both cross-linking and main-chain-breaking reactions in a polymer. Low radiation absorption dose mainly break some weak chemical bonds in a polymer, so bending strength and initial temperature of thermal decomposition (Td) of the composite W/EP-80 (W content of $80 \%$ wt.) decrease from $94.2 \mathrm{MPa}$ and $349.1^{\circ} \mathrm{C}$ to $85.1 \mathrm{MPa}$ and $349.1^{\circ} \mathrm{C}$ respectively. Increasing radiation absorption dose causes inter crosslinking reactions between polymer chains. Finally, further increase in the dose intensifies main chain breaking, which results with degradation of bending strength and Td of the composite W/EP-80.

New composite material was produced, using various amounts of tungsten carbide as a filler and ethylene vinyl acetate copolymer (EVA) as a polymer matrix ${ }^{79}$. The efficiency of material's protective properties against gamma radiation was assessed using Geiger-Müller counter and gamma radiation sources $\left({ }^{137} \mathrm{Cs},{ }^{131}\right.$ I and $\left.{ }^{241} \mathrm{Am}\right)$. Composite disks were made of copolymer by mixing it with 
tungsten carbide (filler content of $50 \%, 60 \%$ and $70 \% \mathrm{wt})$. Compared with lead, the new material is lighter and more flexible, and has better shielding effect. Protective properties of the composite improve along with the increase in WC content. The best shielding effect against gamma radiation was shown by the composite containing WC of $70 \%$ wt. It was also found that such composition had better shielding properties against gamma radiation of high energy, compared with those with low one.

Silicon rubbers are widely used in the aerospace industry, due to their superb electrical insulation properties, operating capacity within wide temperature range and good resistance to fatigue, chemical corrosion, ozone and radiation. Modification ${ }^{80}$ of a silicon rubber by reinforcing it with silicon-oxygen (T-SR) blocks and, additionally, nanoparticles of titan dioxide (M-SR) results in reducing degradation when exposed to proton flux with their energies of 30 to $200 \mathrm{keV}$ and changes in elastic modulus, which increases when exposed to proton radiation with the fluence of $1 \cdot 10^{-14} \mathrm{~cm}^{-2}$ and decreases when their fluence exceeds $1 \cdot 10^{-14}$ $\mathrm{cm}^{-2}$. Addition of nano- $\mathrm{TiO}_{2}$ to silicon rubber does not only improve its mechanical properties, but also improves its resistance to proton radiation.

Addition of nanoparticles of $\mathrm{TiO} 2$ to the matrix of cyanate rubbers ${ }^{81}$ also contributed to improving polymer's radiation resistance, which was accompanied by improvement in bending strength and impact resilience.

PE was widely used in shielding spacecraft, yet the issue was its structural integrity under high pressures and temperature. Creation of a composite with appropriate fillers allows to control mechanical properties. Filling polyethylene with lowdensity silicates ${ }^{82}$ in the form of hollow glass microspheres results in improving tensile resistance and strength while minimizing the increase in the material's weight, which allows to use these impact-resistance composites for protection against high energy radiations during studies and space exploration. At the same time, addition of pure or functionalized boron nitride (15\% vol.) tohigh-density polyethylene ${ }^{83}$ substantially improves elastic modulus of the material, while preserving its shielding effect against high energy neutrons.
Composites based on high-density polyethylene (HDPE) with modified 3-aminopropyltrimethoxysilane-boron-nitride were produces using standard melt extrusion ${ }^{84}$. Properties and characteristics of these composites were compares with the data on composites containing non-modified $\mathrm{BN}$ and boron carbide $\left(\mathrm{B}_{4} \mathrm{C}\right)$. Functionalizing of boron nitride with silicon tetrahydride greatly improves interphase interaction between polymer matrix and filler. As result, HDPE/mBN composites have better degree of scattering (distribution) of filler particles inside the matrix, tensile elasticity modulus and higher heat conductivity coefficient. In terms of neutron-shielding parameters, the composite produced is much better than HDPE/BN and slightly more effective than $\mathrm{HDPE} / \mathrm{B}_{4} \mathrm{C}$ composites, given the same weight contents of fillers. Apart from $B N$ and $B_{4} C$ as reinforcing components for composite materials boron hydrides were proposed ${ }^{85}$. Boron crystalline compounds were proposed to be used, including the derivatives of higher boron-hydrogen anions $\mathrm{B}_{\mathrm{n}} \mathrm{X}_{\mathrm{n}}^{2-} \mathrm{n}=10,12, \mathrm{X}=\mathrm{H}$ (in some cases - halogen, for example, $\mathrm{Cl}$ ) as their respective densities meet the criteria of low weight and high strength needed for composite materials.

UHMWPE is currently widely used as matrix for polymer composites ${ }^{86-91}$. Combining the mixture of boron carbides and tungsten nanopowders as filler for UHMWPE contributed to improving radiation resistance ${ }^{87}$. However, it was demonstrated that addition of large amounts of boron carbide make polymer material fragile.

UHMWPE has a strong ability to slow down fast neutrons, while rear earth metal oxides, such as samarium oxide (III) $\mathrm{Sm}_{2} \mathrm{O}_{3}$, can absorb thermal neutrons. On the basis of these considerations a new composite material was created by hot pressing method, to provide radiation-shielding for UHMWPE $/ \mathrm{Sm}_{2} \mathrm{O}_{3}{ }^{88}$. To improve strength of the bond between $\mathrm{Sm}_{2} \mathrm{O}_{3}$ and UHMWPE, $\mathrm{Sm}_{2} \mathrm{O}_{3}$ surface was modified with bonding agent $\mathrm{KH}-550$ (gammaaminopropy-(trimethoxysilane). Ultimate tensile strength of UHMWPE-based composites shows linear decrease, as the content of $\mathrm{Sm}_{2} \mathrm{O}_{3}$ rises. When filling $\mathrm{Sm}_{2} \mathrm{O}_{3}$, the concentration of tensions in UHMWPE matrix forms and the composite defectiveness rises, which results in decreasing tensile strength ${ }^{89,90}$. In terms of retaining mechanical 
properties, an optimal content of samarium oxide (III) in UHMWPE matrix is $40 \%$ wt. In a similar fashion, gamma/neutron-shielding material based on carbon fabric and polyimid/ $\mathrm{Sm}_{2} \mathrm{O}_{3}$. Composite was produced by hot pressing method. ${ }^{91}$

Using of rare earth elements (e.g. Gd), Sm, Eu or Er)both instead and with boron to develop new radiation-shielding materials is interesting in terms of the neutron capture. It was pointed out ${ }^{92}$ that reaction between neutrons and rare earth elements has an insignificant impact on metal structure and its mechanical properties. Thus, using samarium $(\mathrm{Sm})$ as neutron absorbed provides stable performance of the shielding material over long periods of time. When creating neutron-shielding material (NSM) for effective improvement of mechanical properties, a continuous carbon fiber (0.3-mm thick) was chosen as a base, and polyimide plastics, which have excellent thermal stability, good resistance to chemical corrosion and excellent mechanical properties, which were preliminary modified with $\mathrm{Sm}_{2} \mathrm{O}_{3}$ powder, were chosen as a bonding agent. Regarding the production of impregnating material by simple mixing with a resin, submircon $\mathrm{Sm}_{2} \mathrm{O}_{3}$ powder was chosen to avoid its sedimentation and ensure that a shielding material would possess good mechanical and protective properties.

\section{Polymers filled with layered silicates}

Clay minerals significantly improve mechanical, thermal, electrical and barrier properties of conventional polymers ${ }^{94,96}$. Moreover, they greatly reduce the flammability of polymer composite, competed to pure polymer, Clay minerals are disk-shaped plates and normally have layered structure of tetrahedral and octahedral sheets. Polymer composites containing layered silicates are divided into three different types by method of adding clay to their polymer matrix ${ }^{96}$ : (I) Phase-divided (microcomposites), (II) intercalated (nanocomposites) and (III) exfoliated (nanocomposites). In «phase-divided» polymer composites clay minerals (i.e. layers silicates) are distributed within polymer matrix, yet the polymer does not intrude between layered clay structures However, in both intercalated and exfoliated composites the polymer does intrude into silicates' interlayer space, thus causing the increase in the surface area of phase division between the polymer and filler layers.
Physical and chemical properties of various types of polymer-clay nanocomposites are thoroughly studied. It was also demonstrated that nanocomposites were featured by significant improvement of mechanical properties, thermal stability and corrosion resistance, compared with microcomposites and pure polymers ${ }^{97,98}$. That is why polymer-clay nanocomposites have become widely used in creating construction materials, heatresistant coating, gas-tight materials and materials for electronic industry. In recent years several research teams have been studying radiation resistance of such polymer nanocomposites ${ }^{97-100}$.

Among various types of clay minerals, montmorillonite (MMT) is the most widely used polymer filler, due to its large surface area and reactive ability of its surface. MMT is an aqueous aluminosilicate clay mineral with an octahedral aluminum layer sandwiched between two tetrahedral silicon layers ${ }^{96}$. The thickness of each layers sheet across its length and width is about $1 \mathrm{~nm}$ and 30 to several $\mu \mathrm{m}$ respectively. As the studies showed, various types of MMT-containing polymer nanocomposites have higher resistance to high energy radiation, such as gamma rays and heavy ions. There is a study ${ }^{94,97}$ of the impact the gamma radiation has on nanocomposite based on three block copolymer (styrene-butadiene-styrene) (SBS), intercalated between layers of organophilic MMT (OMMT). According to X-ray diffraction data, when exposed to gamma radiation, nanocomposites SBS/OMMT are subjected to both crosslinking and main chain breaking. DMA results showed that elastic modulus of both pure SBS and nanocomposite SBS/OMMT decreased as the dose rose at the temperature exceeding that of vitrification of one of the components of polymer block SBSpolybutadiene (PB). However, it was found that the decrease in nanocomposite's elastic modulus is less than that of pure SBS. Electronic paramagnetic resonance (EPR) and gel-fractioned measurements showed that there were a larger number of free radicals forming in the nanocomposite, so it is more prone to gel-formation than pure polymer. OMMT layers seem to protect SBS chains from radiation by inoculated copolymerization of broken SBS and OMMT chains.

The same method was used for studying ${ }^{94}$ the impact the gamma radiation has on the morphology and properties of materials based 
on ethylene vinyl acetate copolymer (EVA) with two types of clay minerals used as fillers. Two different OMMT types were produced by cation exchange between Na-MMT and modified agent in aqueous solution, indicated as HOM (produced by exchange of $12.5 \mathrm{~g}$ of Na-MMT and $4.6 \mathrm{~g}$ of hexadecyItrimethylammonium bromide (HOM) andDHOM (derived by exchange reaction between $12.5 \mathrm{~g}$ of Na-MMT and $5.8 \mathrm{~g}$ of 2-metacryloiloksietil hexadecyltrimethylammonium bromide (DHOM). Xray diffraction of these two types of nanocomposites, EVA/HOM and EVA/DHOM, showed that interlayer space and peak intensity of the EVA/DHOM exceeded those of nanocomposite EVA/HOM, which points to a proper intercalation and ordered structure of DHOM clay layers in the EVA matrix. Just like in a previous study, mechanical and thermal properties of nanocomposites EVA/DHOM, which were exposed to radiation, turned out to be better, compared to pure EVA.

It was shown ${ }^{98}$ that under the impact of fast heavy ions (FHI) degradation in nanocomposites polyvinylidenfluoride (PVDF)/ clayswas significantly suppressed, which makes this material an easy-to-use thermoplastic polymer that is resistant to high energy radiation. Intercalation of nanoclay in PVDF increases as the fluence rises. At a large fluence nanocomposites (PVDF)/clay turned out to be capable of re-crystallizing, while pure PVDF finally deteriorates to formation of fragile structure. The crystallinity and melting heat of pure PVDF significantly decrease after having been exposed by $\mathrm{FHI}$, while nanocomposites showed slight changes even at higher flux density.

Similar study ${ }^{99}$ of another polymer, poly (vinylidene fluoride-co-hexafluoropropylene) (HFP), using the same type of nanofiller achieved the results similar to those of PVDF-based nanocomposites. Higher gelatinization and high molecular weight of nanocomposites at higher fluence show that the impact of $\mathrm{FHI}$ mainly causes breaking the chain of non-filled HFP, while nanocomposites are featured by cross-linking.

Based on these studies, multifunctional nanocomposites, poly vinylidene fluoride-cochlorinetrifluoroethylene) (CTFE) with the nanoclay content of $4 \%$ to $8 \%$ wt. (Cloisite $30 \mathrm{~B}$ were developed ${ }^{100}$, which have higher impact resilience, $\mathrm{FHI}$ resistance and piezoelectric properties. Improvement of radiation resistance of nanocomposites CTFE/ nanoclay, compared to pure polymer, occurs due to the preoccupation of crosslinking mechanism by parallel conformation of CTFE molecules in the chain located on the surface of layered nanoclay (i.e. there is a recombination of free radicals that form during the exposure to $\mathrm{FHI}$ ).

\section{CONCLUSION}

In addition to material properties, shielding efficiency of any material depends on numerous factors, which include type of radiation, source (space, nuclear reactor, laboratory, natural radiation and the like), exposure energy range, exposure duration, secondary radiation and other external parameters, such as temperature, pressure and the like. Auxiliary factors that determine the selection of material for effective shieling include materials' compatibility, their cost-efficiency, weight, toxicity, strength and the like. In this regard, polymer composites have a number of advantages, compared to conventional materials. The polymers reinforced with micro- and nanostructures have a huge operational potential as radiation-shielding materials in nuclear power, healthcare and aerospace industry. There is a new trend to develop new multifunctional polymer nanocomposites, which use nanofiller properties to a larger degree.

In nuclear industry materials containing atoms with low atomic number are far from effectively performing continuous attenuation of highly penetrable gamma-rays. One of the solutions, which have recently emerged, is to use gradient shielding material that contains atoms of heavy elements in hydrogen-containing polymer matrix, alongside with other micro and nanomaterials, such as boron, metal oxides, graphite fibers, metal whiskers and the like. The materials containing the mixture of atoms of various atomic numbers, which are added to hydrogencontaining polymer matrix, alongside with some neutron absorbers, are suitable for shielding inside nuclear reactors. Inelastic scattering with heavy atoms and elastic scattering with hydrogen can efficiently block fast and intermediate neutrons, while neutron absorbers can attenuate secondary 
gamma radiation and reduce the impact of thermal neutrons ${ }^{17}$.

Aluminum is conventionally used as a structural material in spacecraft, yet it is heavy, compared to polymer shielding materials. Moreover, aluminum can provide only limited shielding efficiency due to its low electrical density and issues related to formation of secondary particles ${ }^{101}$.

Heavy metals (with high atomic number), such as lead, tungsten, bismuth, litharge or mixture of these substances, have been conventionally used to protect from $\mathrm{X}$-rays and/or gamma rays due to their higher density. As a rule, using lead-based aprons in interventional radiology procedures or other relevant acts causes occupational damage to health, due to the toxicity and weight of leadcontaining products.

The other option is shielding polymerbased materials that are light-weighted and have high processability. They can contain non-toxic fillers that provide effective radiation-shielding ${ }^{102,103}$. The plastics reinforced with carbon/graphite fiberare widely used as structural materials, due to their high hardness-weight ratio and superb mechanical and thermal properties. Selective improvement of nanomaterials' shielding properties, compared to microparticles, is due to increasing number of particles per $1 \mathrm{~g}$ and impact of particles size and surface area. Using nanosized materials in radiation-shielding composites with metal and polymer matrices is also due to the necessity to overcome poor adhesion of matrix materials and radiation-absorbing ceramic particles, and also nanoparticles of heavy metals, which are used as gamma-ray- and X-ray-absorbing fillers.

The diversity of polymer and reinforcing materials allows to specifically control strength, hardness, operating temperature level, radiationshielding and other properties by selecting the content, changing ratio of components and microand nanostructures of the composite. Polymermatrix composites allow to achieve such effect, while preserving material's stability.

\section{ACKNOWLEDGEMENTS}

Applied researches are carried out with state financial support represented by the Ministry of Education of Russia under the Agreement on granting subsidies 14.625.21.0035 of October 27, 2015. (Unique identifier of Applied Scientific Researches (project) RFMEFI62515X0035).

\section{REFERENCES}

1. Cucinotta, F.A., Kim, Y.M., Ren, L. Radiat. Meas. 2006, 41, 1173-1185.

2. Report of the Task Group on the Biological Effects of Space Radiation. Radiation Hazards to Crews on Interplanetary Mission. National Academy of Sciences, Washington, D.C.; 1996.

3. Neutrons. Report on Carcinogens Background Document for X Radiation \& Gamma Radiation and Neutrons. Prepared for U.S. Department of Health and Human Services. Washington, D.C.; 2003.

4. Schimmerling, W., Cucinotta, F.A., Wilson, J.W. Adv. Space Res. 2003, 31, 27-34.

5. Chao, K.S.C. Semin. Radiat. Oncology. 2002, 12, 20-5.

6. Tajiri, M., Tokiya, Y., Uenishi, J., Sunoka, M.,
Watanabe, K. Med. Phys. 2006, 80, 391-393.

7. Sen, S., Schofield, E., O’Dell, J.S., Deka, L., Pillay, S. JOM 2009, 61, 23-31.

8. Good, R.C., Shen, S.P., Dow, N.F. In Active Shielding Concepts for Ionizing Radiation in Space. General Electric Company, Philadelphia, PA, Space Sciences Lab. NASA-CR-58950, 1964.

9. Zezin, A.A., Feldman, V.I. Doklady Akademii Nauk, 2000, 370 (4), 481-485.

10. Zezin, A.A., Feldman, V.I., Egorov, A.V., Shmakova, N.A. Doklady Akademii Nauk, 2004, 394 (5), 631-5.

11. El-Sayed, A., Ali, M.A.M., Ismail, M.R. Radiat. Phys. Chem. 2003, 66, 185-195.

12. Zeitlin, C., Guetersloh, S.B., Heilbronn, L.H., Miller, J. Nucl. Instrum. Methods Phys. Res., 
Sect. B. 2006, 252, 308-318.

13. Stewart, D.Y., Harrison, P.F., Morgan, B., Ramachers, Y. Nucl. Instrum. Meth. Phys. Res., Sect. A. 2007, 571, 651-662.

14. Erdem, M., Baykara, O., Dogru, M., Kuluozturk, F. Radiat. Phys. Chem. 2010, 79, 917-922.

15. Gunduz, G., Usanmaz, A. J. Nucl. Mater. 1986, 140, 44-55.

16. Hu, H.S., Wang, Q.S, Qin, J., Wu, Y.L., Zhang, T.K., Xie, Z.S., Jiang, X.B., Zhang, G.G., Xu, H., Zheng, X.Y., Zhang, J., Liu, W.H., Li, Z.H., Zhang, B.P., Li, L.B., Song, Z.H., Ouyang, X.P., Zhu, J., Zhao, Y.L., Mi, X.Q., Dong, Z.P., Li, C., Jiang, Z.Y., Zhan, Y.P. IEEE Trans. Nucl. Sci. 2008, 55, 2376-2384.

17. Kudriavtsev, G.I., editor. Reinforcing chemical fibers for composite materials. Moscow: Chemistry; 1992.

18. Kabanov, V.Y., Feldman, V.I., Ershov, B.G., Polikarpov, A.I., Kiryukhin, D.P., Apel, P.Y. High Energy Chemistry. 2009, 43(1), 1-18.

19. Milinchuk, V.K., Tupikov, V.I., editors. Radiation resistance of organic materials. Directory. Moscow: Energoatomizdat; 1986.

20. Andrianov, K.A., Slonimskii, G.L., Zhdanov, A.A. Vysokomolekuliarnye soedineniia. 1978, À20 (5), 1066-1073.

21. Aliev, R., Navarro-Gonzalez, R., Medina, R. Polym. Bull. 2006, 57, 499-504.

22. Feldman, V.I. Vestnik Moskovskogo universiteta. Chemistry. 2001, 42(3), 294-304.

23. Nesterov, S.V., Feldman, V.I., Belov, G.P. Polymer Science - Series A. 2002, 44 (9), 947-953.

24. Feldman, V.I., Sukhov, F.F., Orlov, A.Y., Shmakova, N.A. J. Phys. Chem. A. 2000, 104(16), 3792-3799.

25. Pietrzak, M., Wojciehowska, M. Proc. The fourth tihany simpos. on radiation chem. Budapest. 1976, 471-475.

26. Borodinov, N., Giammarco, J., Patel, N., Agarwal, A., O’Donnell, K.R., Kucera, C.J., Jacobsohn, L.G., Luzinov, I. ACS Appl. Mater. Interfaces. 2015, 7(34), 19455-19465.

27. Garcia-Uriostegui, L., Dionisio, N., Burillo, G. Polym Degrad Stab. 2013, 98 (7), 1407-1412.

28. Ferry, M., Bessy, E., Harris, H., Lutz, P.J., Ramillon, J.-M., Ngono-Ravache, Y., Balanzat, E. J. Phys. Chem. B. 2012; 116 (6): 1772-1776.

29. Devasahayam, S., Hill, D.J.T., Connell, J.W. Radiat.
Phys. Chem. 2001, 62, 189-194.

30. Apel, P.Y., Blonskaya, I.V., Oganessian, V.R., Orelovitch, O.L., Trautmann, C. Nucl. Instrum. Methods B. 2001, 185, 216-221.

31. Coltman, R.R., Klabunde, C.E. J. Nucl. Mater. 2001, 103, 717-721.

32. Miakin, S.V., Sychev, M.M., Zagranichek, A.L., Vasileva, I.V., Sosnov, E.A., Kolovangina, E.S. Izvestiia Sankt-Peterburgskogo gosudarstvennogo tekhnologicheskogo instituta (tekhnicheskogo universiteta). 2012, 14, 36-40.

33. Emanuel, N.M., Buchachenko, A.A. Chemical physics of aging and stabilization of polymers. Moscow: Nauka; 1982.

34. Sroog, C.E., Endrey, A.L., Abramo, S.V., Berr, C.E., Edwards, W.M., Olivier, K.L. J. Polym. Sci. A Polym. Chem. 1965, 3(4), 1373-1390.

35. Rubakov, A.P., Florinskii, F.S., Bessonov, M.I. Plasticheskie massy. 1967, 9, 26-29.

36. Pasevich, O.F., Milinchuk, V.K. High Energy Chemistry. 2005, 39 (6), 368-372.

37. Korshak, V.V., Liashevich, V.V., Roda, V.V., Vygodskii, Y.S. Vysokomole kuliarnye soedineniia. 1980, À22(11), 2559-2566.

38. Liaw, D.-J., Wang, K.-L. Prog. Polym. Sci. 2012, 37, 907-974.

39. Kalin, B.A. Radiation resistance of atomic engineering materials. Nauka: Moscow, 1989.

40. Xu, C., Tung, G.A., Sun, S. Chem. Mater. 2008, 20, 4167-4169.

41. Iqbal, H.M.S., Bhowmik, S., Benedictus, R., Moon, J.B., Kim, C.G., Mourad, A.H.I. J. Thermophys. Heat Transfer. 2011, 25, 87-95

42. Bhowmik, S., Benedictus, R. IEEE Applied Electromagnetic Conference. Kolkata. India. 2007.

43. Park, C., Ounaies, Z., Watson, K.A., Pawlowski, K., Lowther, S.E., Connell, J.W., Siochi, E.J., Harrison, J.S., Clair, T.L.St. Polymer'Single Wall Carbon Nanotube Composites for Potential Spacecraft Applications. ICASE Report No. 2002"36. NASA Langley Research Center. Hampton, VA. 2002.

44. Ajayan, P.M., Schadler, L.S., Braun, P.V. Nanocomposite Science and Technology. Wiley-VCH: Weinheim. Germany. 2003.

45. Clayton, L.M., Gerasimov, T.G., Cinke, M., Meyyappan, M., Harmon, J.P. J. Nanosci. Nanotechnol. 2006, 6, 2520-2524. 
46. O'Rourke Muisener, P.A., Clayton, L., D’Angelo, J., Harmon, J.P., Sikder, A.K., Kumar, A., Cassell, A.M., Meyyappan, M. J. Mater. Res. 2002, 17(10), 2507-2513.

47. Atar, N., Grossman, E., Gouzman, I., Bolker, A., Murray, V.J., Marshall, B.C., Qian, M., Minton, T.K., Hanein, Y. ACS Appl. Mater. Interfaces. 2015, 7(22), 12047-12056.

48. Ruan, S.L., Gao, P., Yang, X.G., Yu, T.X. Polymer. 2003, 44, 5643-5654.

49. Singleterry, Jr. R.C., Thibeault, S.A. Materials for Low-Energy Neutron Radiation Shielding; technical report NASA/TP-2000210281. National Aeronautics and Space Administration: Washington, D.C. 2000.

50. Bhattacharya, A. Prog. Polym. Sci. 2000, 25, 371-401.

51. Gul, V.E. Structure and Strength of Polymers. Khimiia: Moscow. 1978.

52. Aleksa, M. X-ray technology. Akademiia nauk Vengrii: Budapest. 1973.

53. Bukanova, N.N., Irdyncheev, L.A., Lushnikova, G.T., Milentev, A.B., Smoliakov, A.V., Sysoev, V.N., Talachev, A.S., Frid, E.S. Patent RF, no. 2066491. 1994.

54. Vogel, R.E. Patent USA, no. US3609372. 1971.

55. Kiriiak, I.I., Pavlenko, V.I., Bryzgalov, lu.D., lartsev, V.A., Zamulin, V.A., Efimov, A.I., Kurtsev, A.E. Patent RF, no. 2077745. 1994.

56. Kushnikova, R.V., Prianikova, G.F. Patent RF, no. 2156509. 1997.

57. International Standard CEI/IEC 1331-3. Protective Devices Against Diagnostic Medical X-radiation. 1994.

58. Andreev, V.V., Barkovskii, A.N., Dobreniakin, lu.P., Kuznetsov, R.A., Miliukhina, G.K., Popkov, K.K., Starostin, B.S., Titov, A.A., Khukharev, V.V. Patent RF, no. 2030803.1995.

59. Blackburn, D.H., Stone, C., Cranmer, D.C., Kauffman, D.A., Grundl, J. Patent USA, no. US5221646.1993.

60. Belorussov, N.I. Electric cables, wires and cords (Reference book). Energoatomizdat: Moscow. 1988.

61. Klimanova, R.S., Sezemova, V.I., Rusakova, M.V., Vasilev, G.A., Orlov, lu.V. Patent RF, no. 2008730. 1994.

62. Ermakov, V.I., Sustavov, V.A., Nurutdinov, M.Kh. Patent RF, no. 2326905. 2008.

63. Richardson, M. Promyshlennye polymernye kompozytsyonnye materyaly [Industrial polymer composite materials]. Khimiia: Moscow. 1980.

64. Goncharov, S.I., Fedotov, V.A. Patent RF, no. 2111559. 1998.

65. Nambiar, S., Yeow, J.T.W. ACS Applied Materials \& Interfaces. 2012, 4 (11), 57175726.

66. Najafi, E., Shin, K. Colloids Surf. A. 2005, 257 258, 333-337.

67. Clayton, L.M., Gerasimov, T.G., Cinke, M., Meyyappan, M., Harmon, J.P. J. Nanosci. Nanotechnol. 2006, 6, 2520-2524.

68. Borjanoviæ, V., Bistrièiæ, L., Mikac, L., McGuire, G.E., Zamboni, I., Jakšiæ, M., Shenderova, O. J. Vac. Sci. Technol. B. 2012, 30(4), 041-803,1-13.

69. Zhong, W.H., Sui, G., Jana, S., Miller, J. Compos. Sci. Technol. 2009, 69, 2093-2097.

70. Shakfa, Z.M., Hannora, A.E., Sherif, M.M. IJRASET. 2015, 3(4), 1046-1049.

71. Hosseini, S.H., Ezzati, S.N., Askari, M. Polym. Adv. Technol. 2015; 26(6): 561-568.

72. El-Kameesy, S.U., El-Nashar, D.E., El-Fiki, S., Agami, W.R., Younes, A.E. IJAR. 2015, 3(6), 1017-1023.

73. El-Sarraf, M.A., El-Sayed Abdo, A. Radiat. Phys. Chem. 2013, 88, 21-26.

74. Maghrabi, H.A., Vijayan, A., Deb, P., Wang, L. Text. Res. J. 2015, 86(6), 649-658.

75. Nambiar, S., Osei, E.K., Yeow, J.T.W. J. Appl. Polym. Sci. 2013, 127(6), 4939-4946.

76. Hubbert, T.E., Vucich, J.J., Armstrong, M.R. Am. J. Roentgenol. 1993, 161, 1079-1081.

77. Aygün, B., Korkut, T., Karabulut, A., Gencel, O., Karabulut, A. Int. J. Polym. Anal. Ch. 2015, 20, 323-329.

78. Chang, L., Zhang, Y., Liu, Y., Fang, J., Luan, W., Yang, X., Zhang, W. Nucl. Instrum. Meth. B. 2015, 356-357, 88-93.

79. Soylu, H.M., Yurt Lambrecht, F., Ersoz, O.A. J. Radioanal. Nucl. Chem. 2015, 305(2), 529534.

80. Di, M., He, S., Li, R., Yang, D. Nucl. Instrum. Methods Phys. Res., Sect. B. 2006, 252, 212218.

81. Qin, W., Peng, D., Wu, X., Liao, J. Nucl Instrum Methods Phys Res B. 2014, 325, 115-119.

82. Ashton-Patton, M.M., Hall, M.M., Shelby, J.E. J. Non-Cryst. Solids. 2006, 352, 615-619. 
83. Harrison, C., Weaver, S., Bertelsen, C., Burgett, E., Hertel, N., Grulke, E. J. Appl. Polym. Sci. 2008, 109, 2529-2538.

84. Shin, J.W., Lee, J.-W., Yu, S., Baek, B.K., Hong, J.P., Seo, Y., Kim, W.N., Hong, S.M., Koo, C. Thermochim. Acta. 2014, 585, 5-9.

85. Popov, V.A., Zhizhin, K.Yu., Malinina, E.A., Retivov, V.M., Kuznetsov, N.T., Staudhammer, K.P. Materials Science Forum. 2008, 587-588, 197-201.

86. Nemeryuk, A.M., Lylina, M.M., Retivov, V.M., Volkov, P.A., Zhdanovich, O.A. Russ. J. Inorg. Chem. 2015, 60 (12), 1548-1555.

87. Kaloshkin, S.D., Tcherdyntsev, V.V., Gorshenkov, M.V., Gulbin, V.N., Kuznetsov, S.A. J. Alloys Compd. 2012, 536 (SUPPL.1), S522-526.

88. Cao, X., Xue, X., Jiang, T., Li, Z., Ding, Y., Li, Y., Yang, H. J. Rare Earth. 2010, 28, 482-484.

89. Xie, X.L., Tang, C.Y., Chan, K.Y., Wu, X.C., Tsui, C.P., Cheung, C.Y. Biomaterials. 2003, 24(11), 1889-1896.

90. Gong, G., Qi, Z., Yang, H. Acta Material Composites Silica (in Chin.). 2002, 19(6), 82-87.

91. Wang, P., Tang, X., Chai, H., Chen, D., Quu, Y. Fusion. Eng. Des. 2015, 101, 218-225.

92. Li, L., Zhaohui, S., Youping, W. China Synth.
Rubber Ind. 2001, 3, 27-34.

93. Yuanyuan, L., Changgui, Z., Dai Shengping, Y.J. Radiat. Prot. 2013, 1, 26-29.

94. Zhang, W., Fang, Y. J. Appl. Polym. Sci. 2005, 98, 2532-2538.

95. Zeng, Q.H., Yu, A.B., Lu, G.Q., Paul, D.R. J. Nanosci. Nanotechnol. 2005, 5, 1574-1592.

96. Kurahatti, R.V., Surendranathan, A.O., Kori, S.A., Singh, N., Ramesh Kumar, A.V., Srivastava, S. Def. Sci. J. 2010, 60, 551-563.

97. Zhang, W., Zeng, J., Liu, L., Fang, Y. J. Mater. Chem. 2004, 14, 209-213.

98. Tiwari, V.K., Kulriya, P.K., Avasthi, D.K., Maiti, P. ACS Appl. Mater. Interfaces. 2009, 1, 311-318.

99. Tiwari, V.K., Kulriya, P.K., Avasthi, D.K., Maiti, P. J. Phys. Chem. B. 2009; 113: 11632"11641.

100. Tiwari, V.K., Shripathi, T., Lalla, N.P., Maiti, P. Nanoscale. 2012, 4, 167-175.

101. Bell, J., Lail, D., Martin, C., Nguyen, P. Radiation Shielding for a Lunar Base. NASA report. National Aeronautics and Space Administration, Washington, D.C.; 2011.

102. McCaffrey, J.P., Mainegra-Hing, E., Shen, H. Med. Phys. 2009, 36, 5586-5594.

103. Yue, K., Luo, W., Dong, X., Wang, C., Wu, G., Jiang, M., Zha, Y. Radiat. Prot. Dosim. 2009, 133(4), 256-260. 